\title{
Unbalance Response Prediction for Rotors on Ball Bearings Using Speed- and Load-Dependent Nonlinear Bearing Stiffness
}

\author{
David P. Fleming \\ NASA Glenn Research Center, Cleveland, OH 44135, USA \\ Email: david.p.fleming@nasa.gov \\ J. V. Poplawski \\ J. V. Poplawski and Associates, Bethlehem, PA 18018, USA \\ Email:jvpoplawski@aol.com
}

Received 12 October 2003

\begin{abstract}
Rolling-element bearing forces vary nonlinearly with bearing deflection. Thus, an accurate rotordynamic analysis requires that bearing forces corresponding to the actual bearing deflection be utilized. For this work, bearing forces were calculated by COBRAAHS, a recently developed rolling-element bearing analysis code. Bearing stiffness was found to be a strong function of bearing deflection, with higher deflection producing markedly higher stiffness. Curves fitted to the bearing data for a range of speeds and loads were supplied to a flexible rotor unbalance response analysis. The rotordynamic analysis showed that vibration response varied nonlinearly with the amount of rotor imbalance. Moreover, the increase in stiffness as critical speeds were approached caused a large increase in rotor and bearing vibration amplitude over part of the speed range compared to the case of constantstiffness bearings. Regions of bistable operation were possible, in which the amplitude at a given speed was much larger during rotor acceleration than during deceleration. A moderate amount of damping will eliminate the bistable region, but this damping is not inherent in ball bearings.
\end{abstract}

Keywords and phrases: rotordynamics, rolling-element bearing stiffness, dynamic analysis, rolling-element bearings, bistable operation.

\section{INTRODUCTION}

Rotordynamic response of all but very flexible rotors depends strongly on bearing properties. When bearings are nonlinear, accurate rotor response calculations require the use of variable bearing properties that reflect the precise conditions encountered, rather than average properties. While fluid film bearings are often reasonably linear for small deflections (although there is usually a strong speed dependence), rollingelement bearings have a much less linear force-displacement relationship.

Analyses of load-stress relationships for rolling-element bearings were published by Lundberg and Palmgren [1]. These relationships were not easily usable until the analytical additions of Jones [2] led to the marketing of his computer code. Jones' code is still the most widely used rolling-element

This is an open access article distributed under the Creative Commons Attribution License, which permits unrestricted use, distribution, and reproduction in any medium, provided the original work is properly cited. bearing analysis tool despite its age. Poplawski et al. [3] recently developed the code computer optimized ball and roller bearing analysis advanced high-speed (COBRA-AHS) under a NASA small business innovative research (SBIR) contract. It is intended to be a major improvement over earlier rollingelement bearing analytical tools. Up-to-date stress/life data, accurate stress calculations considering bearing installation press fits, and an interactive front end are some of its features. It accounts for 5 degrees of freedom in the bearing, and can calculate load-displacement data for high-speed radial and angular contact ball bearings, and also for cylindrical and tapered roller bearings.

In a previous paper by the authors (Fleming and Poplawski [4]), COBRA-AHS was used in conjunction with a transient rotordynamics code to calculate response to a suddenly applied large imbalance simulating a blade loss. The results obtained with nonlinear bearings could not be duplicated with any average bearing stiffness value. In the present paper, nonlinear bearing data from COBRA-AHS is used with a steady-state unbalance response code to calculate 


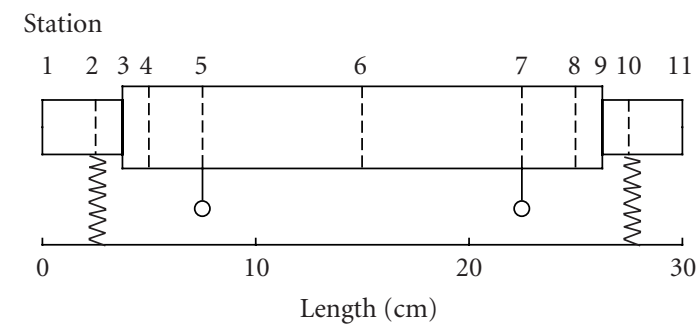

Figure 1: Sketch of rotor.

rotor behavior over a range of speeds, and at imbalance levels representative of normally operating aerospace turbomachinery.

Steady-state rotordynamic response codes have been in use for a number of years. One of the early and still viable codes was formulated by Lund [5]. It uses the transfer-matrix method to calculate unbalance response of a flexible rotor in asymmetric bearings. This code was simplified for the case of symmetric bearings by Kirk [6]. Kirk's code was further modified for the present work to enable the use of nonlinear bearings by iterating on the rotor amplitude.

\section{ANALYTICAL SYSTEM AND PROCEDURE}

Figure 1 is a drawing of the shaft system. It depicts a fairly stiff shaft with concentrated masses (which may represent compressor or turbine wheels) at stations 5 and 7. In total, 11 stations and 10 elements were used in the model. Radial (deep groove) ball bearings of $25 \mathrm{~mm}$ bore diameter are at stations 2 and 10. The shaft material is steel; total mass of the shaft system is $4.6 \mathrm{~kg}$.

Figure 2 shows the first two system critical speeds as a function of bearing stiffness. For stiffness up to about $200 \mathrm{MN} / \mathrm{m}$, critical speeds rise rapidly with stiffness, indicating significant bearing participation in the rotor motion. For higher stiffness values, critical speeds do not increase as rapidly, indicating that increasing amounts of motion are due to shaft bending rather than bearing deflection. Mode shapes calculated at critical speeds, shown in Figure 3 for two values of bearing stiffness, confirm this. For a bearing stiffness of $18 \mathrm{MN} / \mathrm{m}$, most of the elastic deflection takes place in the bearings. At the higher stiffness of $180 \mathrm{MN} / \mathrm{m}$, on the other hand, nearly all of the elastic deflection is in the shaft at the first critical speed, while at the second critical speed there is still large bearing deflection as well as noticeable shaft bending.

COBRA-AHS was used to generate load versus deflection data for the bearings at speeds from 10000 to $80000 \mathrm{rpm}$ and loads from 44 to $8800 \mathrm{~N}$. This data was converted to effective stiffness values by dividing the load by the deflection. A power-series curve of the form $\mathbf{K}=\mathbf{a}+\mathbf{b e}^{\mathbf{c}}$ was then fitted to the stiffness data for each speed, where $\mathbf{K}$ is bearing stiffness, $\mathbf{e}$ is bearing deflection, and $\mathbf{a}, \mathbf{b}$, and $\mathbf{c}$ are coefficients. Cubic polynomials were fitted to the coefficients of the first-curve fit to account for the coefficients' variation with speed. The coefficients resulting from this second-curve fit were then

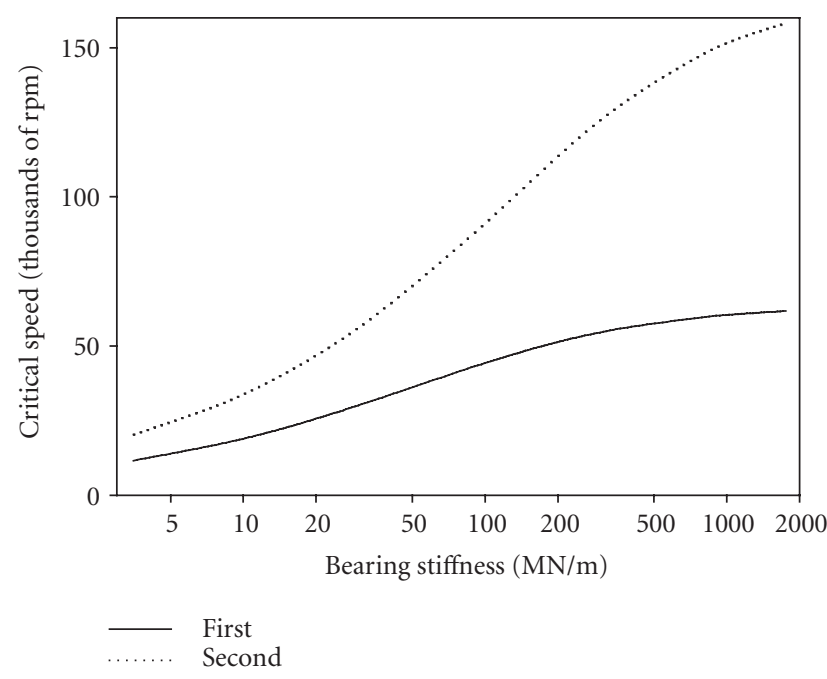

Figure 2: Critical speed map.

supplied to the rotor response code. Figure 4 shows stiffness, that is, load divided by deflection, for several speeds. Both the bearing data and the fitted curves are shown; the curves fit the data very well, verifying that the mathematical representation of the code output is adequate. Note that, for all speeds, there is an order of magnitude change over the range of the figure. This illustrates the significant nonlinearity of the ball bearing used, and is representative of rolling-element bearings. Stiffness decreases as speed increases. This occurs because centrifugal loads cause a deflection within the ball to outer race contact which adds to the deflection due to the applied load; more deflection for the same applied load means lower stiffness. The bearing modeled was not preloaded, but had nearly zero clearance at zero speed; the outward movement of the balls causes the bearing to develop a clearance as speed increases. For the present study, this clearance has negligible effect. However, for a machine subject to external vibration, any clearance is undesirable. Thus ball bearings are commonly given an axial preload to prevent any clearance.

Balancing criteria for rigid rotors are given by international standard ISO 1940 for various classes of rotating machinery (see, e.g., Wowk [7]). These criteria are also commonly used for moderately flexible rotors. The recommended balancing class for aircraft gas turbine assemblies is G6.3. Permissible imbalance is inversely proportional to operating speed. The criteria are conservative, recognizing that considerable balance degradation may occur in service. Imbalance levels studied herein are approximately 4 to 32 times those allowed for the rotor example at $40000 \mathrm{rpm}$, resulting in imbalances of 0.3 to $2.3(\mathrm{~g} \cdot \mathrm{cm})$. The imbalances were applied to the rotor mass at station 7 . Response at stations 7 and 10 (the imbalance and right bearing locations) was examined for speeds of 20000 to $80000 \mathrm{rpm}$. Although larger than allowed by the standard for a well-balanced rotor, these imbalances are considerably less than those produced by a blade loss; Fleming and Poplawski [4] used imbalances of 3.6 to $57.6 \mathrm{~g} \cdot \mathrm{cm}$ in their study of transient vibration. 


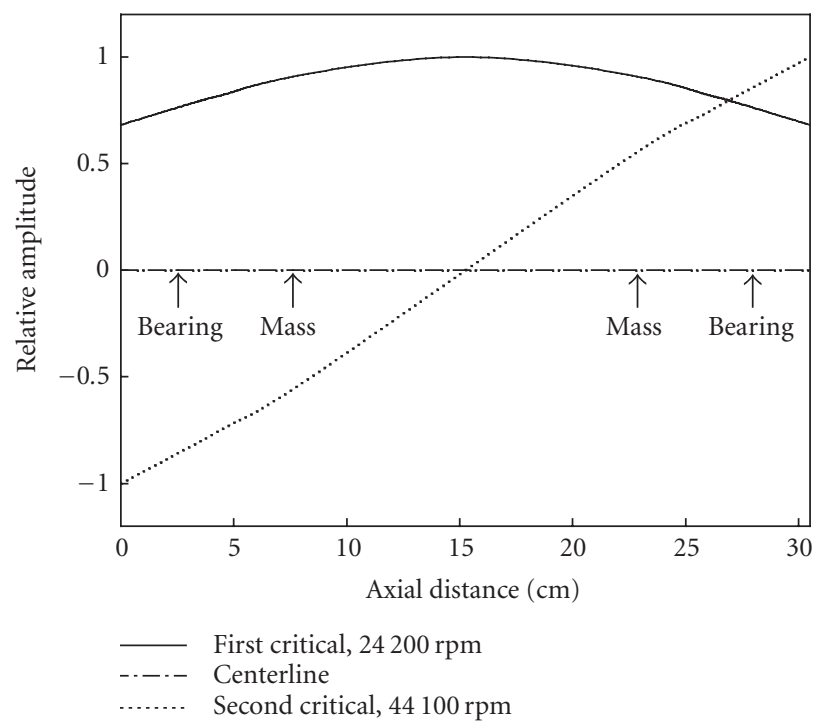

(a)

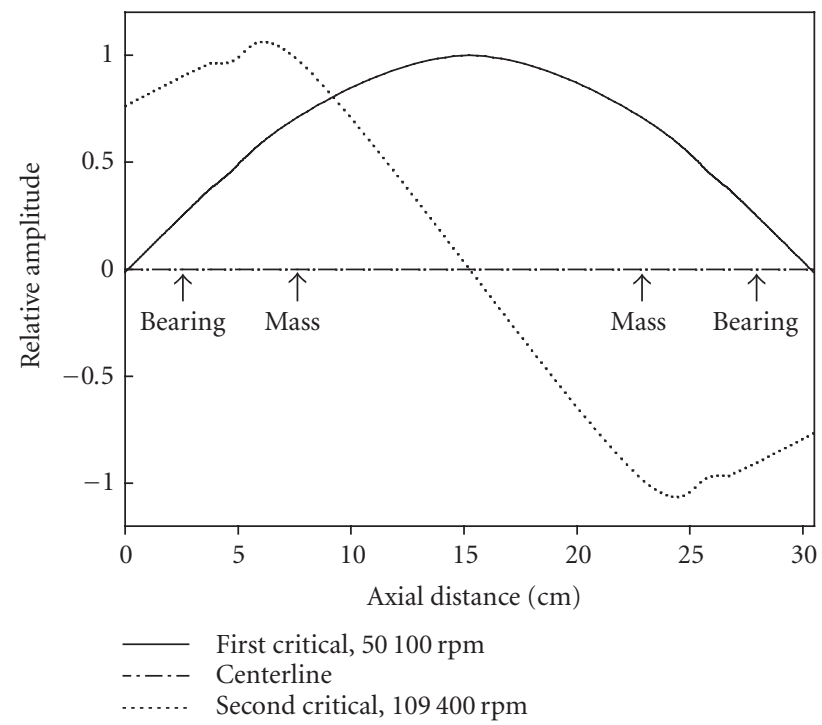

(b)

FIgURE 3: Critical speed mode shapes. (a) Bearing stiffness $=18 \mathrm{MN} / \mathrm{m}$. (b) Bearing stiffness $=180 \mathrm{MN} / \mathrm{m}$.

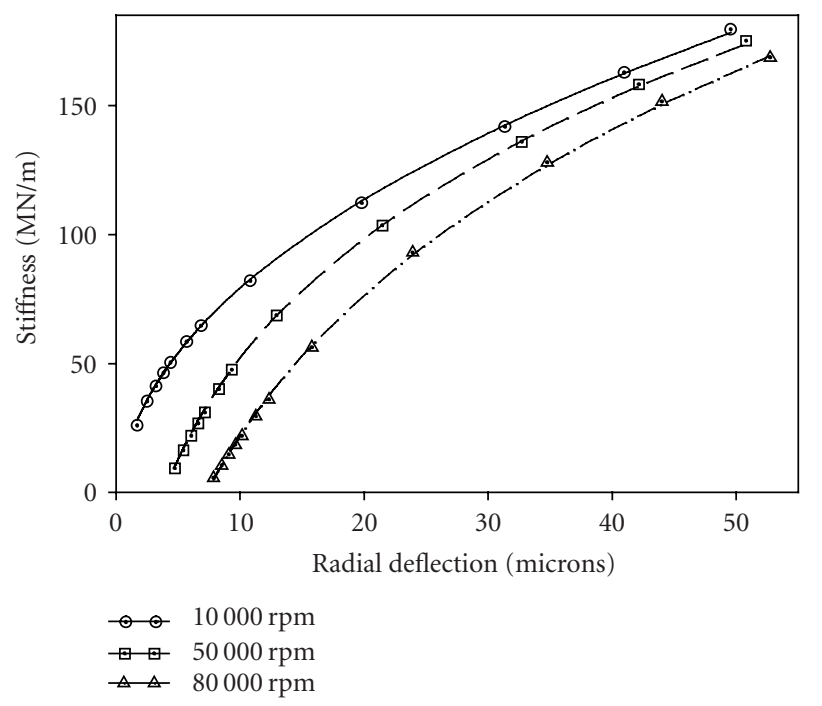

FIGURE 4: Ball bearing stiffness. Symbols denote data from COBRAAHS and lines denote fitted curves.

\section{RESULTS}

Synchronous vibration amplitude at bearing station 10 is shown in Figure 5 for imbalances of $0.6,1.2$, and $2.3 \mathrm{~g} \cdot \mathrm{cm}$. The most notable feature of this figure is the portrayal of bistable operation: at some speeds, amplitude can assume one of two values, depending on the rotor history. Arrows on the curves in Figures 5, 6, 7, 8, 10, 11, 12, and 13 show whether speed was increasing or decreasing when the information was generated. For discussion purposes, we will focus on the data for $1.2 \mathrm{~g} \cdot \mathrm{cm}$ imbalance (dotted lines in the figures). As speed rises above $30000 \mathrm{rpm}$, vibration amplitude increases as is usual when running up to a critical speed.

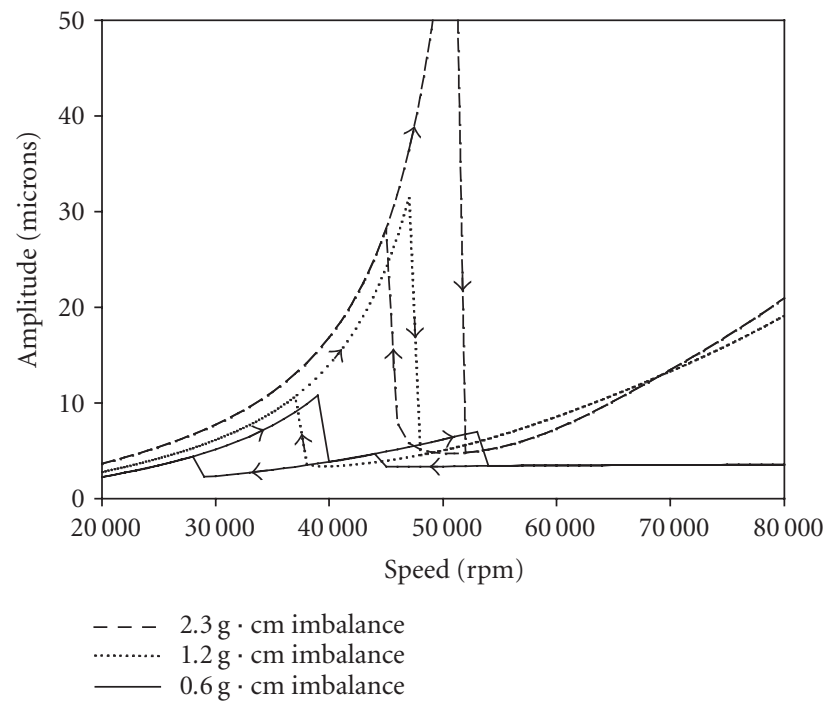

FIgUre 5: Station 10 amplitude.

This results in an increase in bearing load, shown in Figure 6. Since ball bearing stiffness increases with amplitude, there is also an increase in bearing stiffness as speed increases (Figure 7). This in turn raises the critical speed (Figure 2), so the operation remains subcritical longer than would occur with constant-stiffness bearings. Rotor bending increases with stiffness (and thus with speed), as can be seen by comparing Figure 3a with Figure 3b. Finally, at $48000 \mathrm{rpm}$, the critical speed is passed even at the large bearing stiffness. Supercritical operation begins suddenly as the amplitude jumps down to a low value. For this case, the operation is now also above the second critical speed, as can be discerned from Figure 2 and the bearing stiffness plotted in Figure 7. Further 


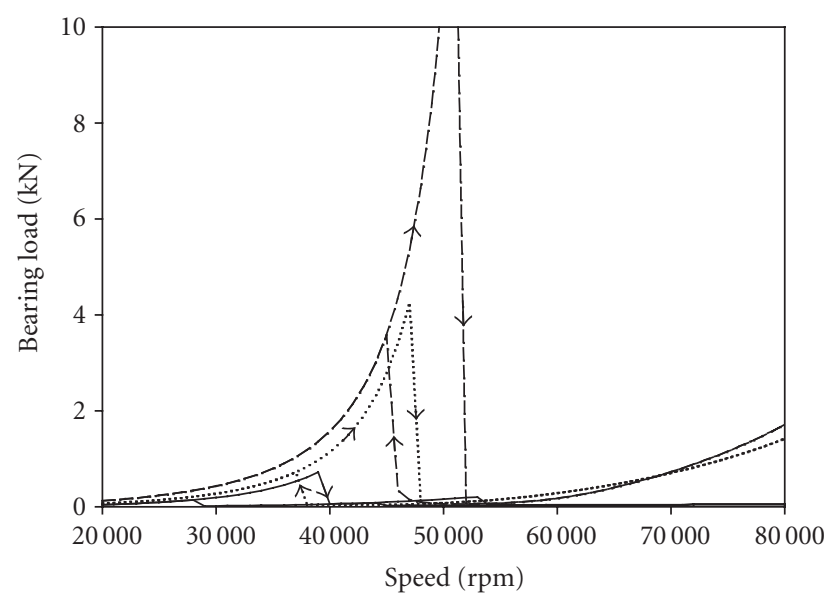

- - $2.3 \mathrm{~g} \cdot \mathrm{cm}$ imbalance

....... $1.2 \mathrm{~g} \cdot \mathrm{cm}$ imbalance

- $0.6 \mathrm{~g} \cdot \mathrm{cm}$ imbalance

FIgURE 6: Station 10 bearing load.

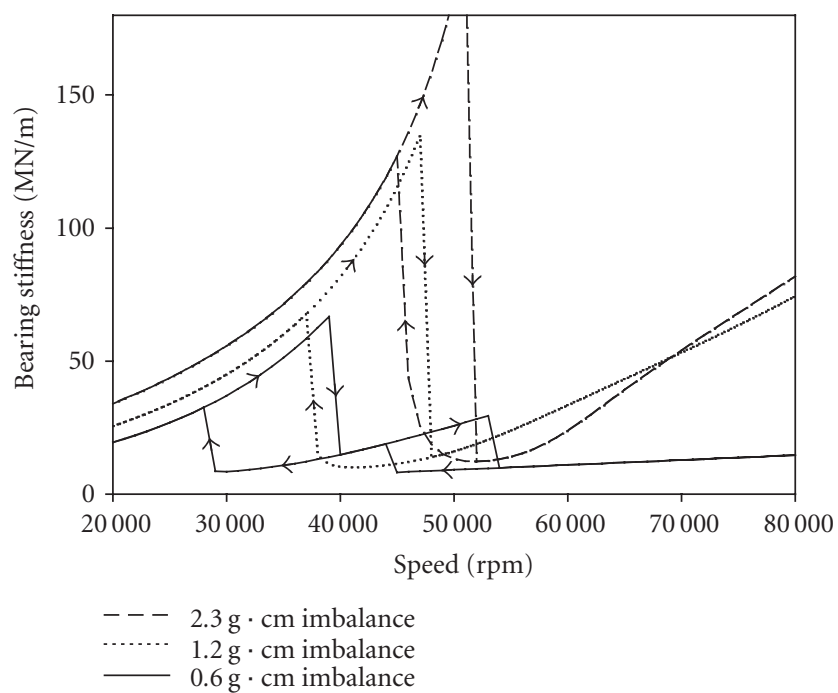

Figure 7: Bearing stiffness at station 10.

increases in speed produce an increase in amplitude as the third critical speed (above $200000 \mathrm{rpm}$ for all bearing stiffnesses investigated) is approached.

When speed is decreased from the maximum, the supercritical mode shape results in a low bearing stiffness down to $37000 \mathrm{rpm}$ where the amplitude jumps up to rejoin the curve for increasing speed.

Vibration amplitude for station 7 (the location of the imbalance) is shown in Figure 8. The appearance of this figure is similar to Figure 5, but the amplitudes are higher as the critical speeds are approached because of rotor bending. Mode shape plots in Figure 9 illustrate this. In this figure, mode shapes at $43000 \mathrm{rpm}$ are shown for both increasing and decreasing speed. Because the rotor mode is a combination of the first and second critical speed mode shapes, the rotor shape is not strictly planar. This is shown in the figure by

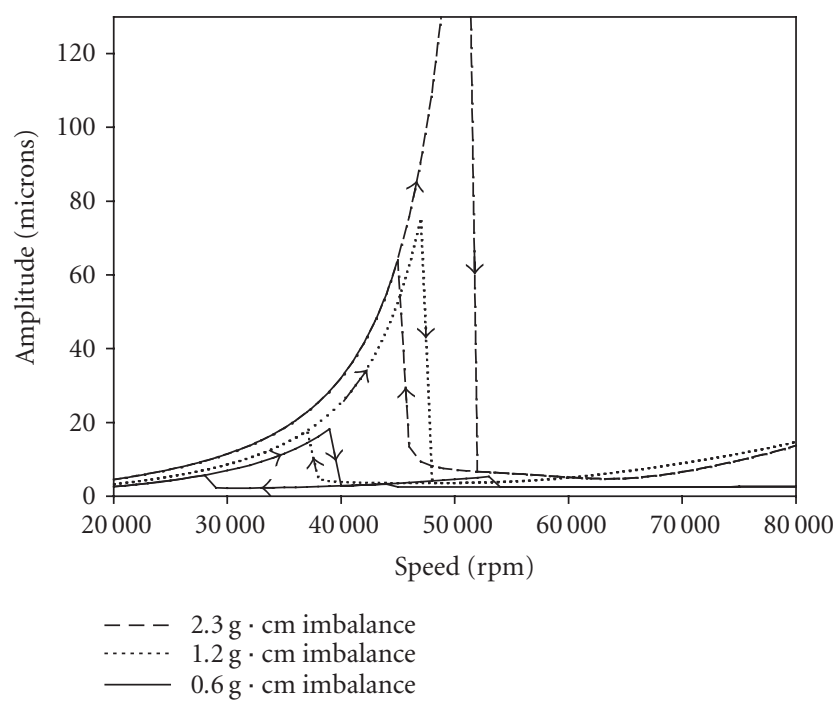

FIgURe 8: Station 7 amplitude.

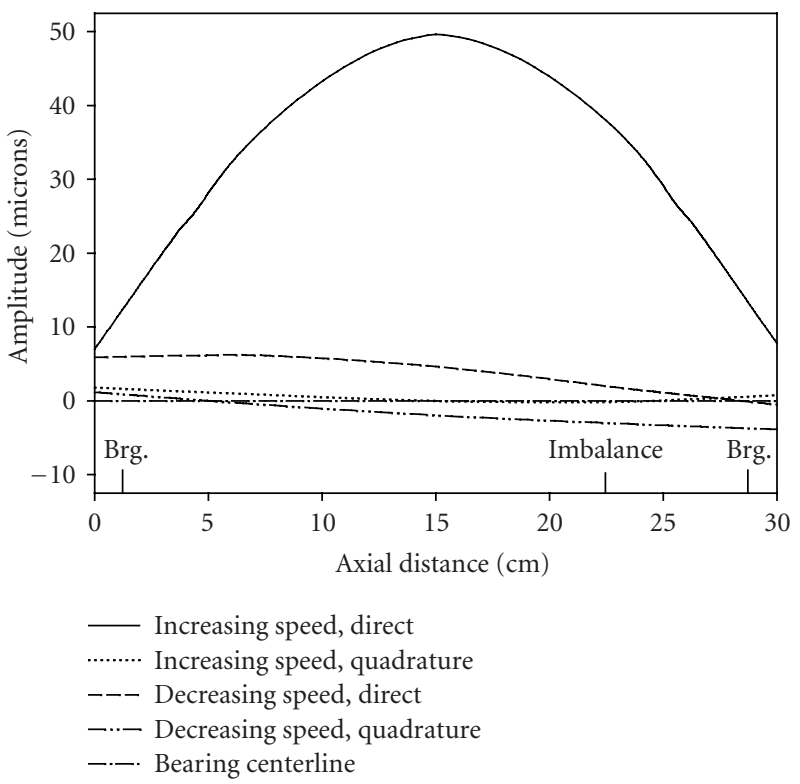

FIgURE 9: Rotor mode shapes, $43000 \mathrm{rpm}, 1.2 \mathrm{~g} \cdot \mathrm{cm}$ imbalance.

plotting two curves for each mode; the first is the amplitude in the direction of maximum displacement (labeled direct), and the second is at right angles to this (labeled quadrature). For increasing speed, with operation below the first critical speed and high bearing stiffness, there is a considerable rotor bending. The quadrature component is quite small, indicating a nearly planar mode shape as the first critical speed mode dominates. For decreasing speed, the mode is nearly a straight line with amplitude much lower than for increasing speed. In this case, however, the quadrature component is significant, indicating a combination of modes.

In each of Figures 5, 6, 7, and 8, the data for $0.6 \mathrm{~g} \cdot \mathrm{cm}$ imbalance (solid lines) indicate not one, but two regions of bistable operation. For this imbalance case, the first and 


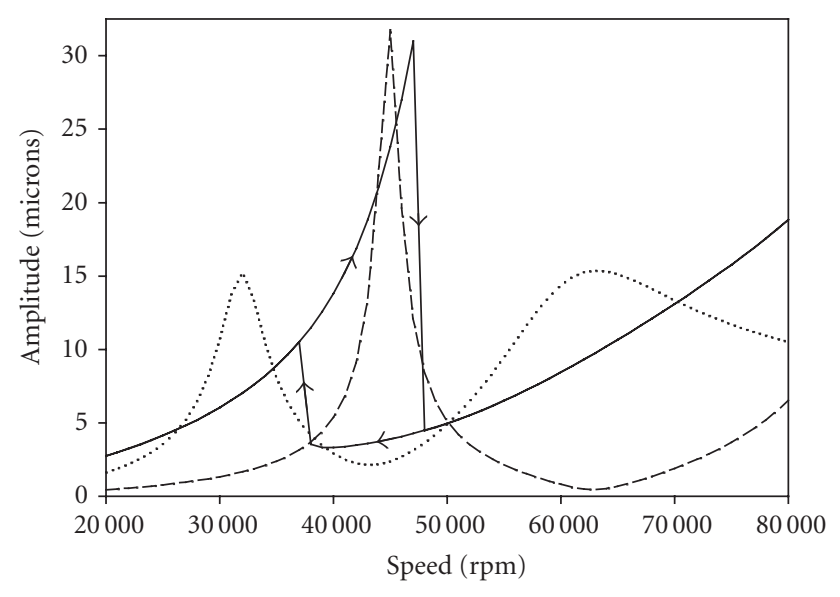

_ Variable stiffness from COBRA-AHS

…… $35 \mathrm{MN} / \mathrm{m}$

- - $105 \mathrm{MN} / \mathrm{m}$

FIGURE 10: Station 10 amplitude for fixed and variable bearing stiffness; imbalance $=1.2 \mathrm{~g} \cdot \mathrm{cm}$.

second critical speeds are traversed one at a time, rather than simultaneously as occurs with higher levels of imbalance.

Bistable operation has been observed both analytically and experimentally on rotors supported by squeeze-film dampers (e.g., Simandiri and Hahn [8]). The reasons it occurs are the same as discussed above, since squeeze-film damper stiffness increases with vibration amplitude similar to the behavior of a ball bearing. Indeed, bistable operation is a well-recognized phenomenon of nonlinear systems (Meirovich [9]). However, to the authors' knowledge, bistable operation for rotors supported by nominally undamped ball bearings has not been reported. This is perhaps because most high-speed rotors, particularly those that must traverse critical speeds, are supported on damped bearings.

\section{Comparison with constant-stiffness bearings}

Figure 10 shows vibration amplitude at bearing station 10 for an imbalance of $1.2 \mathrm{~g} \cdot \mathrm{cm}$. Two fixed values of stiffness ( 35 and $105 \mathrm{MN} / \mathrm{m}$, which nearly bracket the stiffnesses shown in Figure 7) were studied; the variable-stiffness case of Figure 5 is also shown for comparison. The curves for constant stiffness show classical rotor behavior, with a degree of symmetry around the peak amplitude. At the lower $(35 \mathrm{MN} / \mathrm{m})$ stiffness, two critical speeds are traversed. For the higher $105 \mathrm{MN} / \mathrm{m}$ stiffness, only one critical speed appears below $80000 \mathrm{rpm}$. This is consistent with the critical speed map of Figure 2. The variable-stiffness case exhibits higher amplitude than the $105 \mathrm{MN} / \mathrm{m}$ case over most of the speed range during runup. During rundown, however, critical speed passage does not occur until the speed has dropped to $37000 \mathrm{rpm}$, and peak amplitude is much lower than during runup because supercritical operation is maintained until jump up.

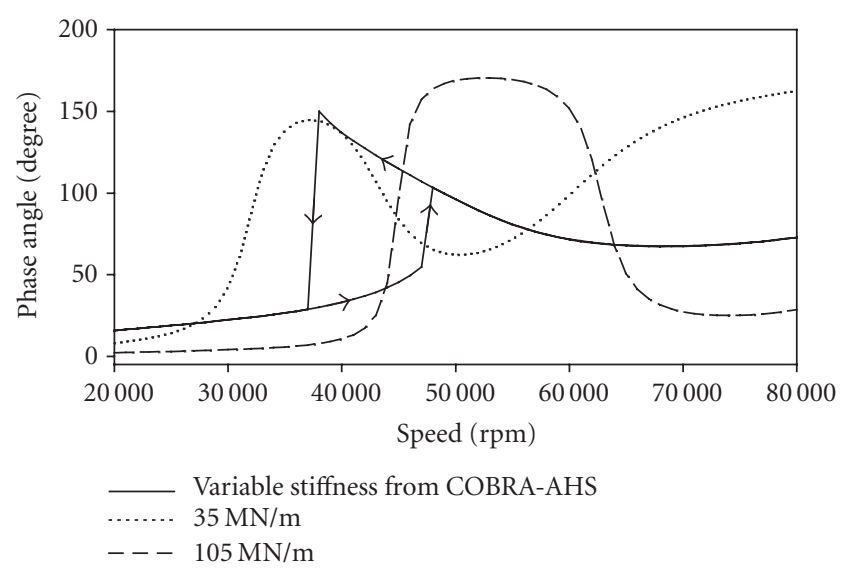

FIgURE 11: Station 10 phase angle.

Further insight into rotor behavior may be obtained by examination of the rotor phase angles, defined as the angle by which the imbalance force leads the displacement (this definition is equivalent to the more common definition for the present case of a single unbalance mass, and makes the results easier to understand). Figure 11 plots the phase angle at bearing station 10 for the same conditions as in Figure 10. For all bearing-stiffness cases, the phase angle is initially small but increases as the first critical speed is approached. Total phase change for the fixed-stiffness cases is close to the 180 degrees predicted in classical rotor studies. When variablestiffness from COBRA-AHS is used, phase change is considerably less, but this may be explained by recalling that the rotor remains subcritical until a jump up to the supercritical operation occurs; at this point, because of much lower bearing deflection, the rotor is well into the supercritical region. During rundown, a larger phase-angle change occurs before the jump than during runup, so that the phase angle just before the jump down is nearly equal to the $35 \mathrm{MN} / \mathrm{m}$ stiffness case. Above the critical speed, the phase angle decreases for all stiffness cases, contrary to expectation. For the $35 \mathrm{MN} / \mathrm{m}$ stiffness case, the phase angle begins to rise again with speed as the second critical speed is approached.

The anomalous behavior of the phase angle decreasing with increasing speed may be explained by looking at the difference in the phase angle between the two bearings. This is shown in Figure 12. At low speed, the phase-angle difference is small, as expected for a translatory or bowed mode shape as shown in Figure 3a for the first critical speed. Above the critical speed, the two bearings are out of phase, as for the second critical speed of Figure 3a. In the speed range of bistable operation (with variable bearing stiffness), the phase angle during runup and rundown shown in Figures 11 and 12 may be studied along with the $43000 \mathrm{rpm}$ mode shape plots of Figure 9. During runup, the bowed mode shape is nearly symmetric about the rotor axial midpoint; the operation is still well within the subcritical region, resulting in small phase angles that are nearly the same for the two bearings. During rundown, however, the operation is supercritical at $43000 \mathrm{rpm}$ (above both the first and second critical 


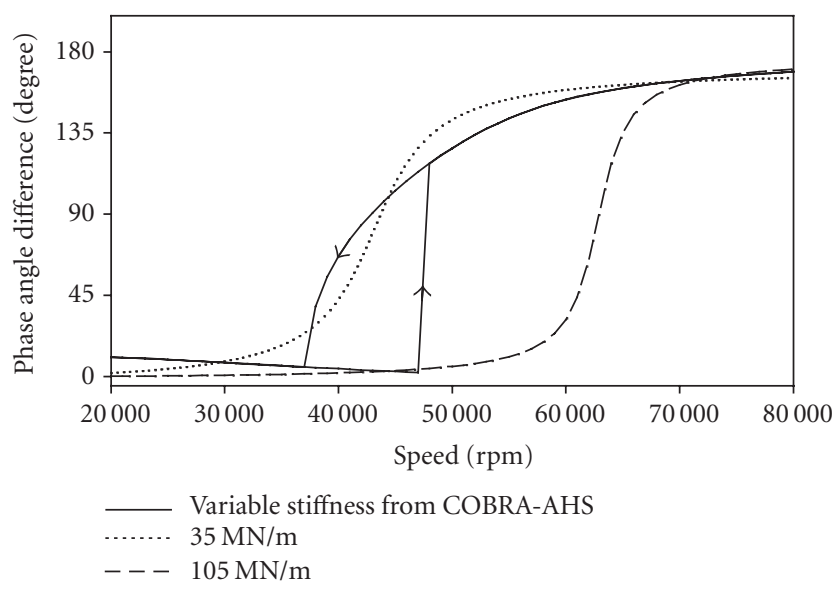

FIgure 12: Phase angle difference between bearings.

speeds, as discussed above). The rotor has assumed a nonplanar but near-conical mode shape, resulting in the two bearings being out of phase by 90 degrees. Although not shown, the bearing at station 2 presents a more classical behavior, with phase angles increasing by nearly 180 degrees as the rotor passes through the critical speed.

\section{Effect of bearing damping}

It is known that ball bearings have very low inherent damping, but little data is available on actual damping coefficients. Lewis and Malanoski [10] mention values of 2.6 to $3.5 \mathrm{kN} \mathrm{s} / \mathrm{m}$ for a greased-packed bearing, but do not give the source of the data. Zeillinger and Köttritsch [11] describe experiments on an oil-lubricated $45 \mathrm{~mm}$ bearing. They took care to exclude damping of the bearing mount and include only the damping occurring within the bearing itself. Values of 0.5 to $1 \mathrm{kN} \mathrm{s} / \mathrm{m}$ were measured; for the smaller 25 $\mathrm{mm}$ bearing used in the present study, one would expect less damping than this. Zeillinger and Köttritsch did note that additional damping usually occurs between the bearing outer race and its housing. However, this damping would be effective only for small vibration amplitude because of the small clearance between bearing and housing in typical installations.

For the data presented above, bearing damping of $1.8 \mathrm{kN} \mathrm{s} / \mathrm{m}$ was assumed. Figure 13 shows the effect of other damping values for the case of $1.2 \mathrm{~g} \cdot \mathrm{cm}$ imbalance. Damping of $3.5 \mathrm{kN} \mathrm{s} / \mathrm{m}$ (twice that used above) reduces the peak amplitude considerably at bearing station 10 and separates the first and second critical speeds. However there is still a region of bistable operation. A somewhat higher damping of $5.3 \mathrm{kN} \mathrm{s} / \mathrm{m}$ eliminates the bistable region entirely. This damping value is not large compared to what is prescribed for optimally damped rotors; however, it is more than can be expected from a ball bearing. Thus, as noted above, ball-bearing-supported rotors that are designed for operation near or above critical speeds usually incorporate dampers.

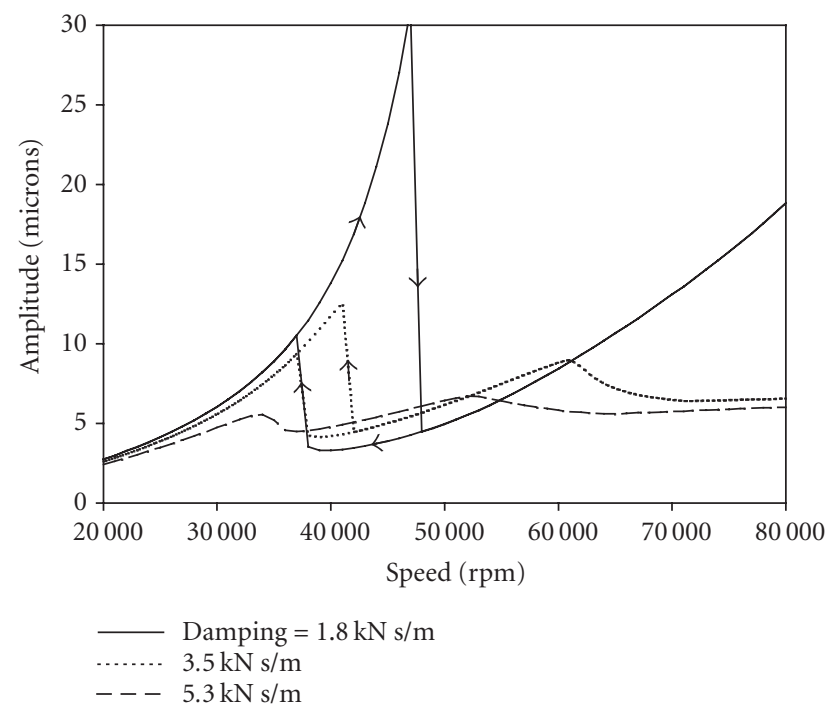

FIGURE 13: Station 10 amplitude for various damping values; imbalance $=1.2 \mathrm{~g} \cdot \mathrm{cm}$

\section{CONCLUDING REMARKS}

Unbalance response data was presented for a rotor supported on ball bearings with accurate bearing stiffness calculated as a function of speed and load. Bearing stiffness was found to be a strong function of bearing deflection, with higher deflection producing markedly higher stiffness. Rotordynamic analysis showed that unbalance response varied nonlinearly with the amount of rotor imbalance. Moreover, the increase in bearing stiffness as critical speeds were approached caused a large increase in rotor and bearing vibration amplitude over part of the speed range compared to the case of constantstiffness bearings. Regions of bistable operation were possible, in which the amplitude at a given speed was much larger during rotor acceleration than during deceleration. A moderate amount of damping eliminated the bistable region, but this damping is not inherent in ball bearings.

\section{REFERENCES}

[1] G. Lundberg and A. Palmgren, "Dynamic capacity of rolling bearings," Acta Polytechnica Mechanical Engineering Series, vol. 1 , no. 3, 1947.

[2] A. B. Jones, "A general theory for elastically constrained ball and radial roller bearings under arbitrary load and speed conditions," Trans. ASME, J. Basic Eng., vol. 82, no. 2, pp. 309320, 1960 .

[3] J. V. Poplawski, J. H. Rumbarger, S. M. Peters, R. Flower, and H. Galaitis, "Advanced analysis package for high speed multibearing shaft systems: COBRA-AHS," Final report, NASA Contract NAS3-00018, 2002.

[4] D. P. Fleming and J. V. Poplawski, "Transient vibration prediction for rotors on ball bearings using load-dependent nonlinear bearing stiffness," International Journal of Rotating Machinery, vol. 10, no. 6, pp. 489-494, 2004.

[5] J. W. Lund, Rotor-Bearing Dynamics Design Technology; Part V: Computer Program Manual for Rotor Response and Stability. AFAPL-TR-65-45, 1965. 
[6] R. G. Kirk, Nonlinear transient analysis of multimass flexible rotors, Ph.D. Dissertation, University of Virginia, Charlottesville, Va, USA, 1972.

[7] V. Wowk, Machinery Vibration, McGraw Hill, New York, NY, USA, 1994.

[8] S. Simandiri and E. J. Hahn, "Experimental evaluation of the predicted behaviour of squeeze-film-bearing-supported rigid rotors," Journal of Mechanical Engineering Science, vol. 21, no. 6, pp. 439-451, 1979.

[9] L. Meirovich, Elements of Vibration Analysis, McGraw-Hill, New York, NY, USA, 1975.

[10] P. Lewis and S. B. Malanoski, Rotor-Bearing Dynamics Design Technology; Part IV: Ball Bearing Design Data. AFAPL-TR-6545, 1965.

[11] R. Zeillinger and H. Köttritsch, "Damping in a rolling bearing arrangement," Evolution, 1/96, 1996. 

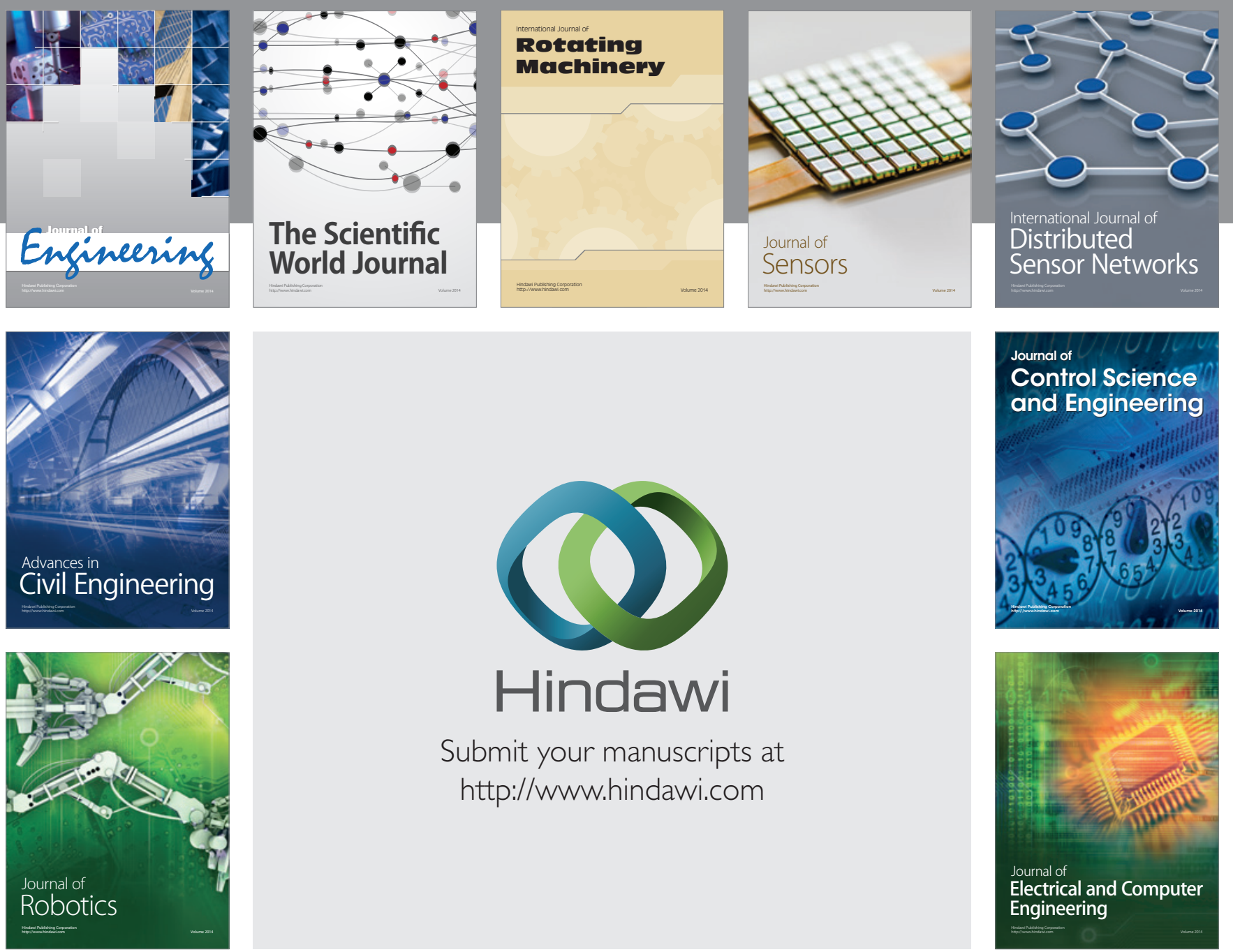

Submit your manuscripts at

http://www.hindawi.com
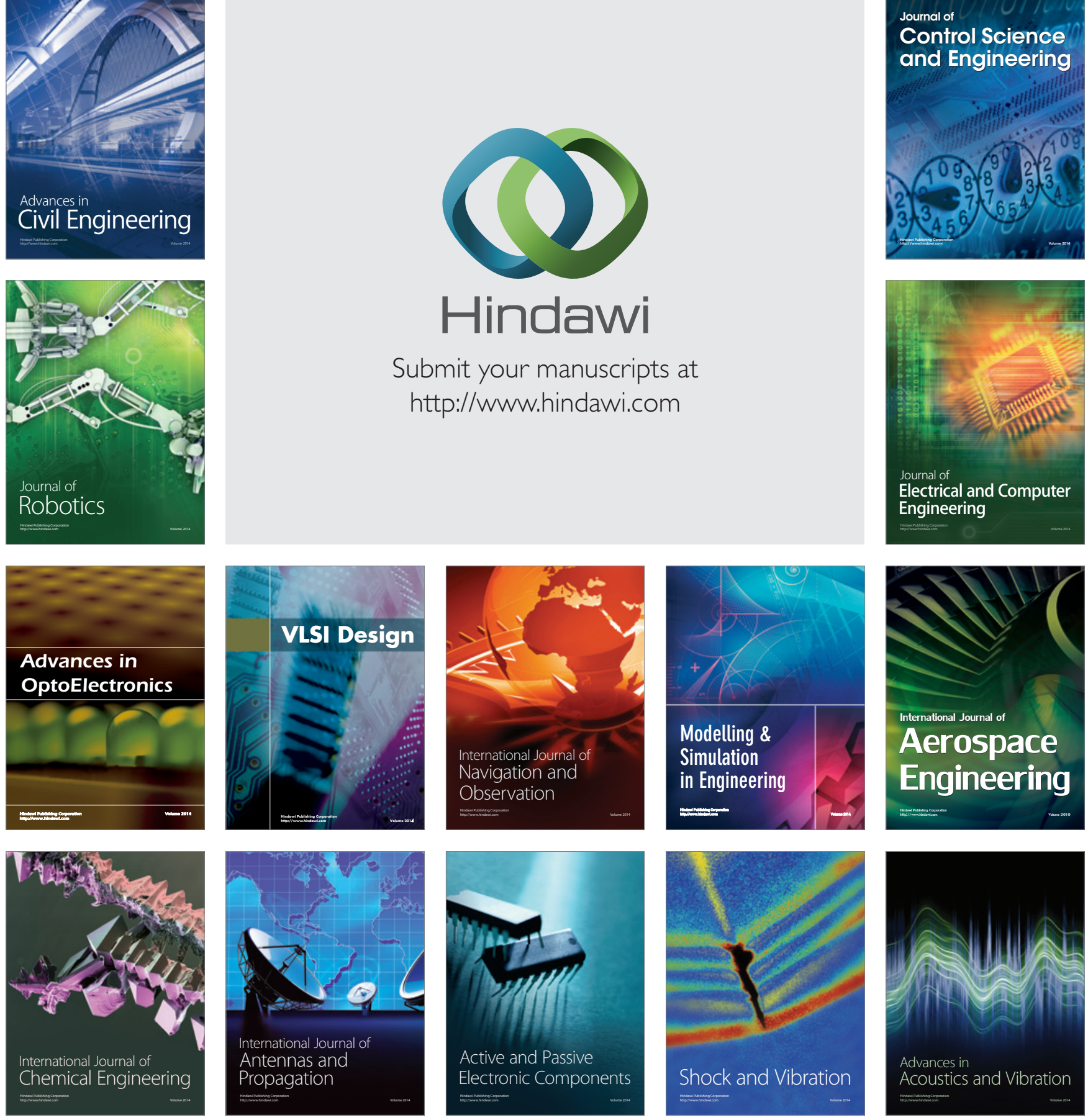